\title{
Volatiles from the tropical ascomycete Daldinia clavata (Hypoxylaceae, Xylariales)
}

\author{
Tao Wang ${ }^{1}$, Kathrin I. Mohr ${ }^{2}$, Marc Stadler ${ }^{2}$ and Jeroen S. Dickschat ${ }^{* 1}$
}

\section{Full Research Paper}

\section{Address:}

${ }^{1}$ Kekulé-Institut für Organische Chemie, Universität Bonn, Gerhard-Domagk-Straße 1, 53121 Bonn, Germany and ${ }^{2}$ Abteilung für Mikrobielle Wirkstoffe, Helmholtz-Zentrum für Infektionsforschung, Inhoffenstraße 7, 38124 Braunschweig, Germany

Email:

Jeroen S. Dickschat ${ }^{*}$ - dickschat@uni-bonn.de

* Corresponding author

Keywords:

enantioselective synthesis; gas chromatography; mass spectrometry; natural products; volatiles

\author{
Beilstein J. Org. Chem. 2018, 14, 135-147. \\ doi:10.3762/bjoc. 14.9 \\ Received: 16 November 2017 \\ Accepted: 04 January 2018 \\ Published: 12 January 2018 \\ Associate Editor: K. N. Allen \\ (C) 2018 Wang et al.; licensee Beilstein-Institut. \\ License and terms: see end of document.
}

\begin{abstract}
The volatiles from the fungus Daldinia clavata were collected by use of a closed-loop stripping apparatus and analysed by GC-MS. A few compounds were readily identified by comparison of measured to library mass spectra and of retention indices to published data, while for other compounds a synthesis of references was required. For one of the main compounds, 5-hydroxy-4,6-dimethyloctan-3-one, the relative and absolute configuration was determined by synthesis of all eight stereoisomers and gas chromatographic analysis using a homochiral stationary phase. Another identified new natural product is 6-nonyl-2H-pyran-2-one. The antimicrobial and cytotoxic effects of the synthetic volatiles are also reported.
\end{abstract}

\section{Introduction}

A large variety of volatile organic compounds from different compound classes including fatty acid derivatives and polyketides, aromatic compounds, terpenes, sulfur and nitrogen compounds, and halogenated compounds is produced by ascomycete fungi [1]. Possibly the most widespread volatile secondary metabolite from fungi is $(R)$-oct-1-en-3-ol (1, Scheme 1), a compound that was first isolated from Tricholoma matsutake and named "matsutake alcohol" [2,3]. This odourous volatile is responsible for the typical mushroom smell of many fungi and also contributes to the pleasant aroma of edible mush- rooms such as the button mushroom, Agaricus bisporus [4]. Another widespread fungal volatile is 6-pentyl-2H-pyran-2-one (2) that was first isolated from Trichoderma and exhibits a strong coconut aroma [5]. For fungi producing $\mathbf{2}$ a plant-growth promoting effect and an induction of systemic resistance in plants has been observed which makes these fungi interesting as biocontrol agents [6]. On the contrary, fungi can also produce mycotoxins, which must be excluded for their safe usage in agricultural biocontrol. Some volatiles, especially terpenes, point to the production of certain toxins in fungi, e.g., aris- 


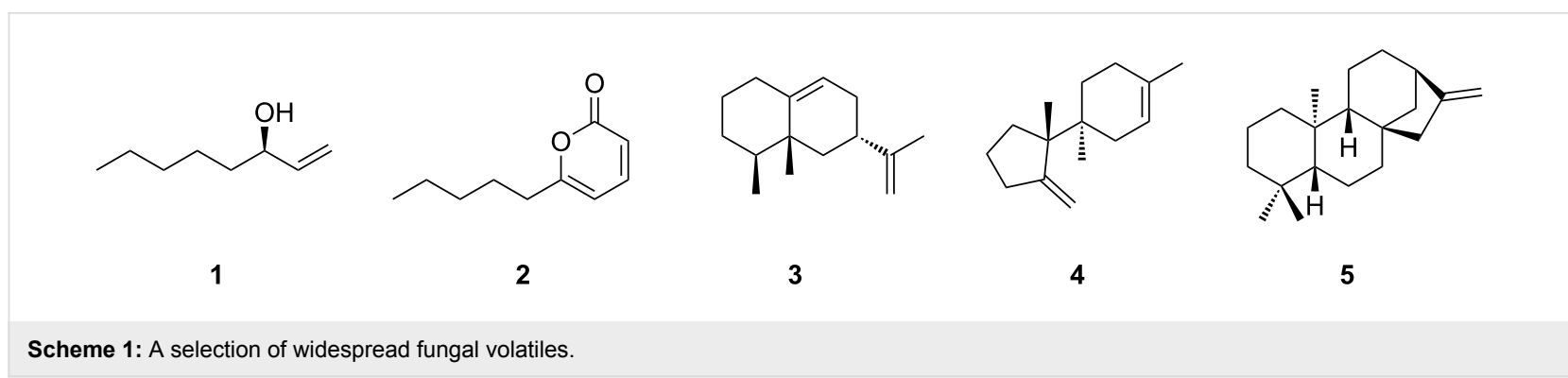

tolochene (3) is the precursor of PR toxin in Penicillium roqueforti [7-9], trichodiene (4) is the parent hydrocarbon of the trichothecene family of mycotoxins in various Trichothecium and Fusarium strains [10], and the diterpene ent-kaurene (5) is the precursor of gibberellins, a class of plant hormones that are produced in large amounts by the rice pathogen Fusarium fujikuroi and other fusaria $[11,12]$. The potential beneficial bioactivity and role in the intra- or interspecies communication as well as the possible function as markers for toxin production recently resulted in an increasing interest in volatile secondary metabolites in the scientific community.

The Xylariales (class Sordariomycetes) is one of the largest orders of Ascomycota and comprises several thousands of microscopic fungi, as well as numerous "macromycetes" that may produce conspicuous fruiting bodies (stromata) [13]. The Xylariaceae remain the largest family of this order, even though it was recently further divided, based on a multi-gene phylogeny that widely agreed with important chemotaxonomical and morphological traits [14]. A comprehensive overview of the current taxonomy of these families has been published by Daranagama et al. [15].

However, still only little is known about volatile secondary metabolites from Xylariales. Most respective studies have been dedicated to some endophytic strains that can be assigned to the Xylariales based on preliminary molecular phylogenetic data and are being referred to the suggested genus Muscodor. However, this genus was recently rejected, because its erection did not follow good taxonomic standards [14]. The only comparative study available on the production of volatiles that used taxonomically well-characterised Xylariales relied on a panel of strains of the genera Daldinia and Hypoxylon and some allied genera that were previously included in the Xylariaceae, but have recently been reassigned to the Hypoxylaceae [16]. Since many of the compounds observed during GC-MS analyses in the volatile profiles of these fungi could not be identified with confidence in the latter study, we have selected some of these strains for intensified evaluation. Here, we present the identification, synthesis and bioactivities of volatiles emitted by the rare tropical hypoxylaceous ascomycete Daldinia clavata, which has hitherto been only infrequently reported from Africa and Latin America.

\section{Results and Discussion Headspace analysis}

The volatiles emitted by agar plate cultures of Daldinia clavata MUCL 47436 grown on YMG medium were collected on charcoal filter traps by application of a closed-loop stripping apparatus (CLSA) [17]. Dichloromethane extracts of the charged filters were analysed by GC-EIMS, followed by identification of the captured volatiles by comparison of the recorded mass spectra to data base spectra (NIST and Adams [18]) and of measured retention indices to reported data. For unknown compounds a structural proposal was developed by interpretation of the mass spectra, followed by the synthesis of reference compounds for unambiguous verification of the suggested structures.

\section{Volatiles from Daldinia clavata identified by GC-MS}

A representative total ion chromatogram of a CLSA headspace extract from D. clavata is shown in Figure 1. Several of the emitted volatiles were readily identified from their mass spectra and retention indices, including 4-methylhexan-3-one (6), oct-1en-3-ol (1), octan-3-one (7), 1-phenylethanol (8), and pogostol (16), which was further confirmed by comparison to authentic standards for 1, 7 and $\mathbf{8}$ (Table 1 and Scheme 2). Furthermore, the two structurally and biosynthetically related compounds 2-methyl-4-chromanone (12) and 5-hydroxy-2-methyl-4-chromanone (13) were tentatively identified from their mass spectra. Compound 13, which exhibits antimicrobial activity, was previously isolated from various species of Daldinia [16,19-22] and several endophytic fungi, the latter of which have only been tentatively characterised at the genus level [23-28]. The compound actually consitutes one of several chemotaxonomic marker metabolites for the clade in the Hypoxylaceae comprising Daldinia and allied genera [29]. The sesquiterpene alcohol 16 was first isolated from the plant Pogostemon cablin (patchouli) [30], but is also known from fungal sources [31,32]. We show here the corrected structure as reported by Amand et al. [31], while for the compound from patchouli oil the opposite absolute configuration has been assigned [33]. The 


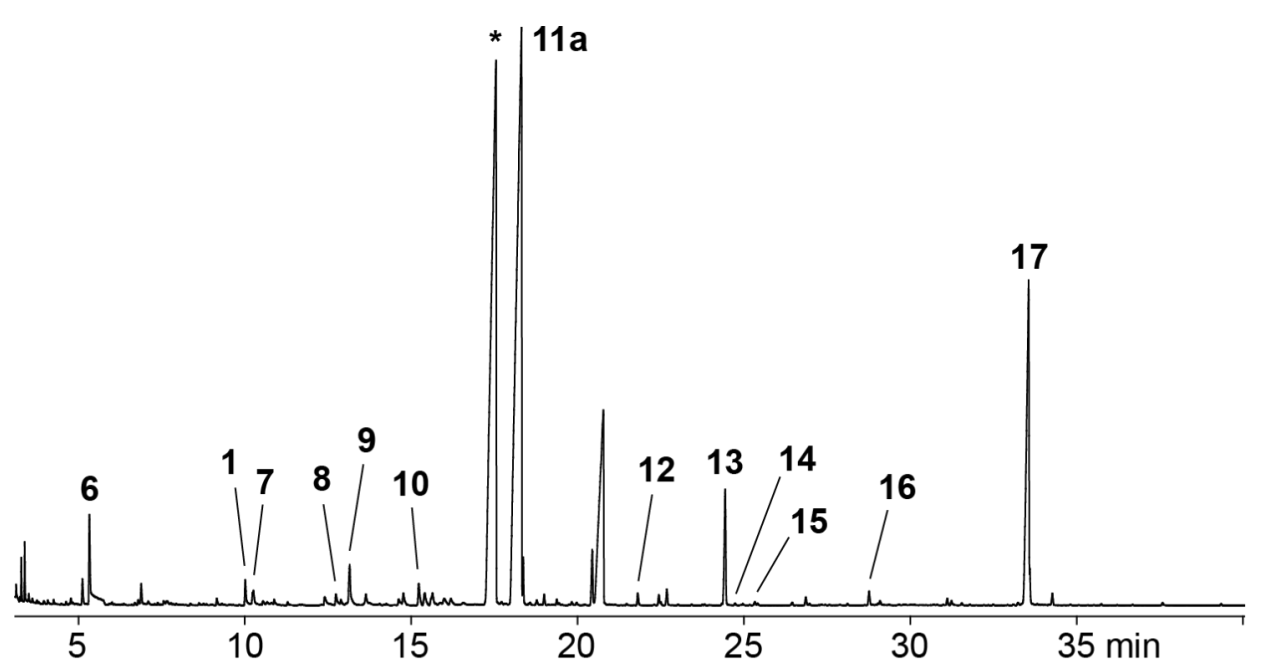

Figure 1: Total ion chromatogram of a representative headspace extract from Daldinia clavata MUCL 47436. Peak numbers refer to compound numbers in Scheme 2. The peak labelled with an asterisk represents an unidentified natural product from $D$. clavata.

\begin{tabular}{|c|c|c|c|c|}
\hline Compound & I & I (Lit.) & Identification ${ }^{a}$ & Peak area ${ }^{b}$ \\
\hline 4-methylhexan-3-one (6) & 845 & $842[34]$ & $\mathrm{ms}, \mathrm{ri}$ & $2.0 \%$ \\
\hline oct-1-en-3-ol (1) & 981 & $974[18]$ & $\mathrm{ms}, \mathrm{ri}, \mathrm{std}$ & $0.4 \%$ \\
\hline octan-3-one (7) & 988 & $979[18]$ & ms, ri, std & $0.4 \%$ \\
\hline 1-phenylethanol (8) & 1060 & $1057[18]$ & $\mathrm{ms}$, ri, std & $0.2 \%$ \\
\hline 6-methyl-5,6-dihydro-2H-pyran-2-one (9) & 1072 & - & syn & $0.9 \%$ \\
\hline manicone (10) & 1136 & - & ms, syn & $0.4 \%$ \\
\hline$(4 R, 5 R, 6 S)-5$-hydroxy-4,6-dimethyloctan-3-one (11a) & 1228 & - & syn & $35.2 \%$ \\
\hline 2-methyl-4-chromanone (12) & 1366 & - & $\mathrm{ms}$ & $0.2 \%$ \\
\hline 5-hydroxy-2-methyl-4-chromanone (13) & 1467 & - & $\mathrm{ms}$ & $2.0 \%$ \\
\hline 1,3-dichloro-2,4-dimethoxybenzene (14) & 1480 & $1487[18]$ & $\mathrm{ms}, \mathrm{ri}, \mathrm{std}$ & $0.03 \%$ \\
\hline 1,2,4-trichloro-3-methoxybenzene (15) & 1504 & - & $\mathrm{ms}, \mathrm{std}$ & $0.1 \%$ \\
\hline pogostol (16) & 1653 & $1651[18]$ & ms, ri & $0.3 \%$ \\
\hline 6-nonyl-2H-pyran-2-one (17) & 1875 & - & syn & $9.7 \%$ \\
\hline
\end{tabular}

aldentification based on ms: identical mass spectrum, ri: identical retention index (standardised GC retention based on comparison to $n$-alkanes; for $\mathrm{C}_{n} \mathrm{H}_{2 n+2}$ the retention index is defined as $I=100 \cdot n$ ), std: comparison to a commercially available standard compound, syn: comparison to a synthetic standard. ${ }^{b}$ Peak area in \% of total peak area. The sum is less than $100 \%$, because compounds originating from the medium, unidentified compounds and contaminants such as plasticisers are not mentioned.

absolute configuration of $\mathbf{1 6}$ from Daldinia clavata remains unknown.

The headspace extracts from D. clavata also contained two chlorinated compounds as indicated by the isotope pattern of the molecular ions in the respective EI mass spectra. The first of these compounds was readily identified as 1,3-dichloro-2,4dimethoxybenzene (14) by comparison to an authentic standard and to synthetic standards of all possible positional isomers. These isomers have been made accessible during our previous work that resulted in the identification of 1,5-dichloro-2,3- dimethoxybenzene as a headspace constituent of an endophytic Geniculosporium sp. [35]. The mass spectrum of the second compound pointed to the structure of 1,2,4-trichloro-3methoxybenzene (15) which was confirmed by comparison to a commercially available reference. Chlorinated anisoles are well known as drinking water contaminants that can be sensed by humans with extremely low detection limits [36]. Their origin by biomethylation of the corresponding phenols is frequently discussed, but the de novo formation of compounds $\mathbf{1 4}$ and $\mathbf{1 5}$ without administration of the corresponding phenols has not been reported before. 


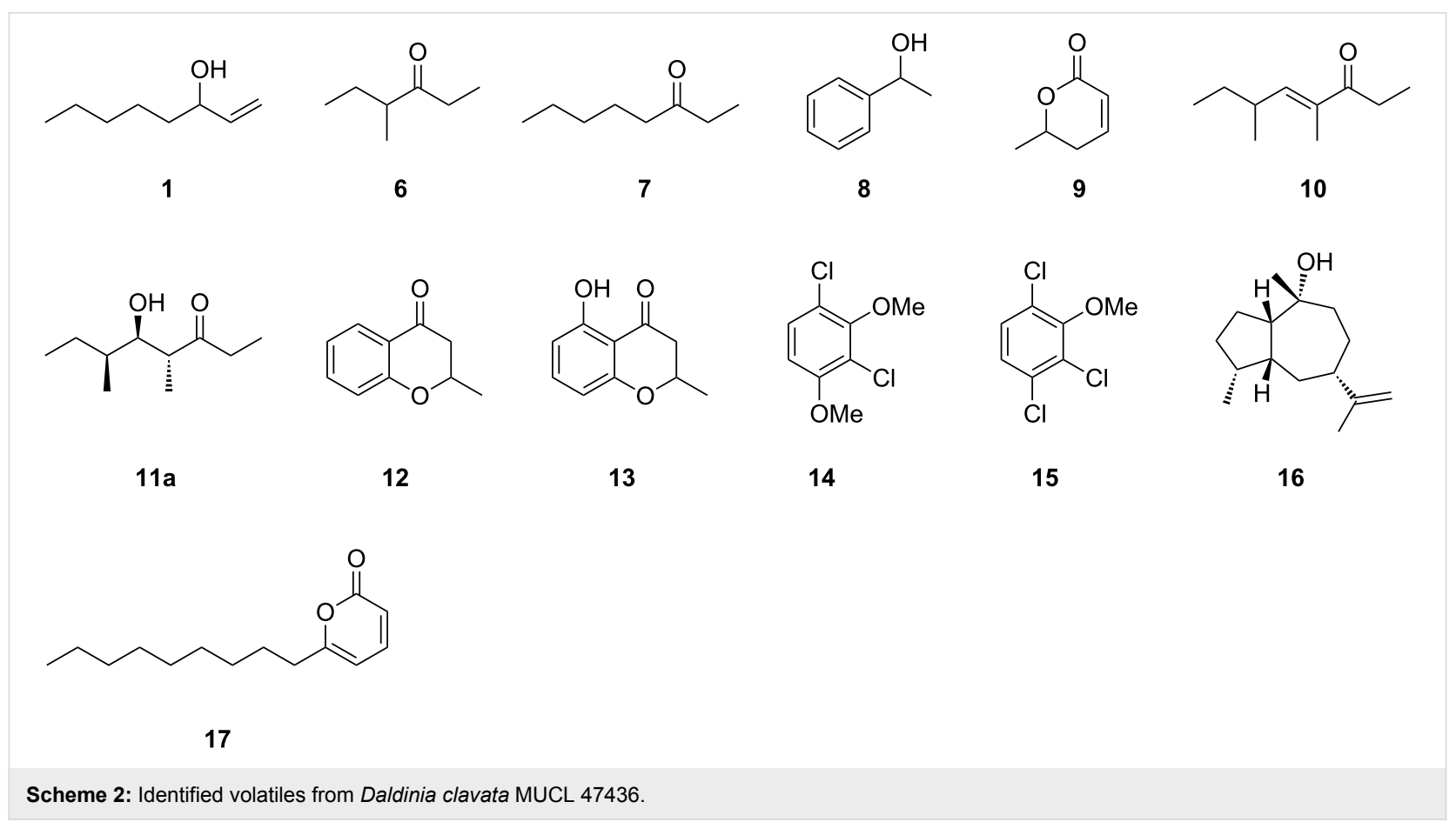

\section{Volatiles from Daldinia clavata identified by synthesis}

Several other compounds released by $D$. clavata could not unambiguously be identified based on GC-MS data only. In these cases structural proposals were delineated from the recorded EI mass spectra and the suggested structures were proven by synthesis of a reference compound. The first compound showed a mass spectrum (Figure 2A) that was similar to a data base spectrum of manicone ( $(E)$-4,6-dimethyloct-4-en-3-one, 10), but no retention index for this compound was available from the literature. For unambiguous structural verification compound $\mathbf{1 0}$ was synthesised starting from 2-methylbutanal (18, Scheme 3). A Horner-Wadsworth-Emmons reaction with triethyl 2-phosphonopropionate (19) yielded ethyl $(E)$-2,4-dimethylhex-2enoate (20) as a separable mixture of $E$ and $Z$ stereoisomers $(E / Z=10: 1)$. The purified $E$ diastereomer was reduced with DIBAl-H to the corresponding alcohol 21. A PCC oxidation and addition of ethylmagnesium bromide gave $\mathbf{2 2}$ that was subsequently oxidised with PCC to the target compound 10. Comparison of the natural product to synthetic $\mathbf{1 0}$ established their identity by same retention time and mass spectrum.

The mass spectrum of one of the two main compounds (11a) in the headspace extracts (Figure 2B) showed some fragment ions that were also observed for $\mathbf{1 0}$, suggesting that the two volatiles may be structurally related. The fragment ions at $m / z=57$ and $m / z=86$ supported the structure of a 4-methyl-3-ketone (these ions would arise by $\alpha$-cleavage and McLafferty rearrangement). Biosynthetically, $\mathbf{1 0}$ is a tetraketide, and if the dehydration step to install the $\mathrm{C}=\mathrm{C}$ double bond in $\mathbf{1 0}$ would be omitted, this would lead to the hydroxy-ketone 11a for which a higher retention time than for $\mathbf{1 0}$ would be expected. The structure of such an alcohol was further supported by the fragment ion at $\mathrm{m} / \mathrm{z}=115$ that may result from an $\alpha$-cleavage next to the alcohol function. To verify this structural proposal for 11a, racemic 2-methylbutanal (18) was reacted in an aldol addition with the enolate anion of pentan-3-one (23) which produced a racemic mixture of all four diastereomers 11a-d (Scheme 4). All eight stereoisomers of $\mathbf{1 1}$ were separable by GC on a homochiral stationary phase, one of which matched the natural product in terms of same retention times and mass spectra (Figure 3).

To clarify the relative and absolute configuration of the natural stereoisomer of $\mathbf{1 1}$ an enantioselective synthesis was performed (Scheme 5). The alcohol (S)-2-methylbutan-1-ol (24) was converted into the corresponding aldehyde by Swern oxidation, followed by the addition of $\mathbf{2 5}$ to yield the esters $(2 E, 4 S)$ - and $(2 Z, 4 S)-20$ as a mixture of diastereomers (ca. 15:1) that was readily separated by column chromatography. The $E$ isomer was reduced with DIBAl-H to $\mathbf{2 6}$ that was converted into the epoxide 27a by Sharpless epoxidation with (+)-L-DET. Treatment with TBSOTf and Hünig's base resulted in opening of the epoxide with concomitant hydride migration to yield 28a. The stereochemical course for this reaction has been reported by Jung and D'Amico [37] and proceeds with inversion of configuration at $\mathrm{C}-2$. Grignard reaction with ethylmagnesium bromide to $29 \mathrm{a}$, PCC oxidation to $\mathbf{3 0 a}$ and deprotection with HF-pyri- 

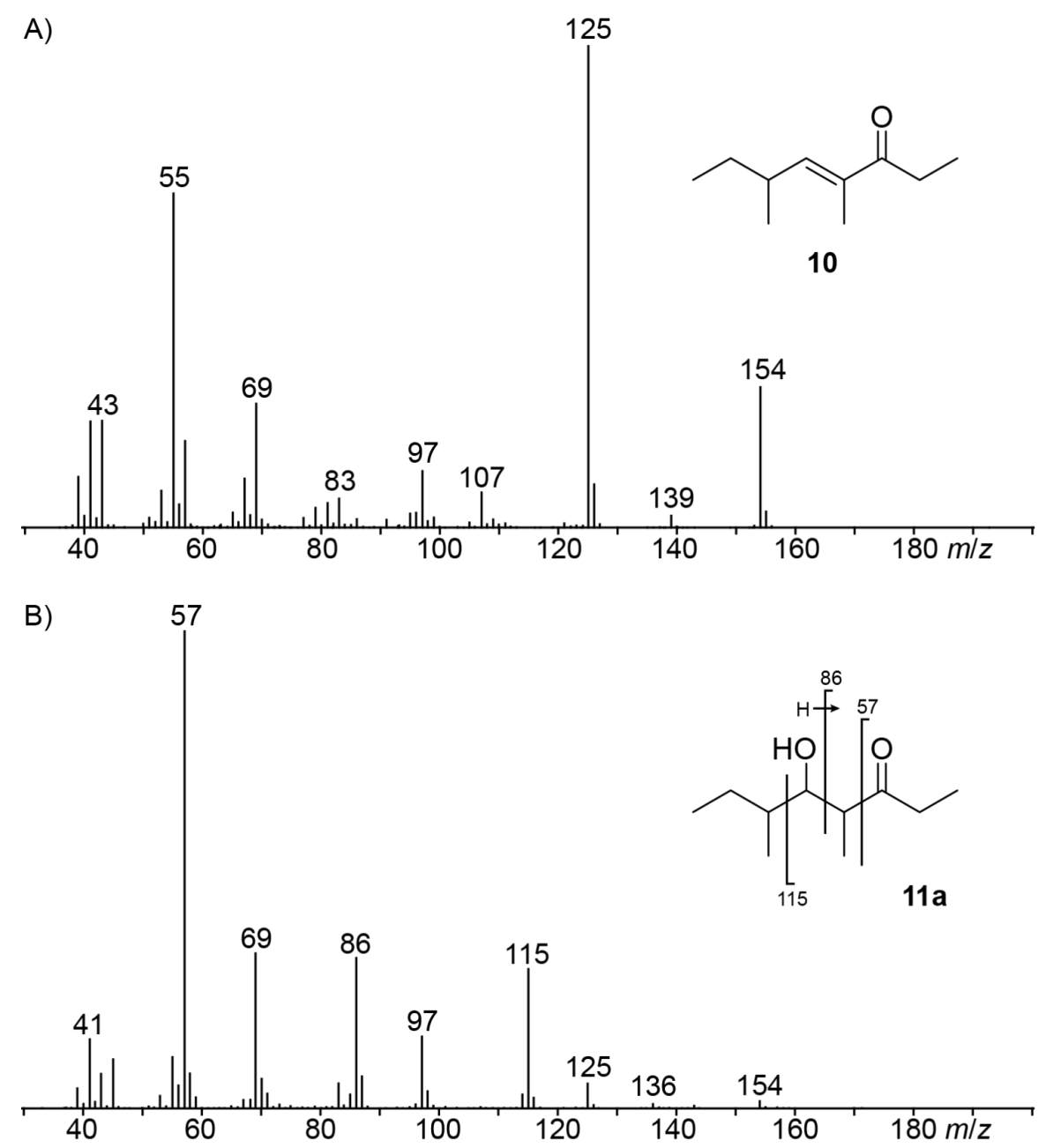

Figure 2: Mass spectra of volatiles from $D$. clavata that were identified by synthesis.

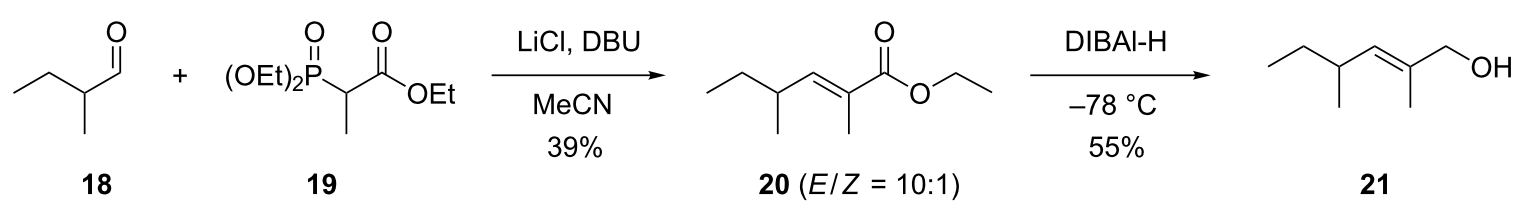<smiles>CCC(=O)/C(C)=C/C(C)CC</smiles>

Scheme 3: Synthesis of manicone (10).

dine gave access to $(4 R, 5 S, 6 S)$-11 $\mathbf{c}$ with an overall yield of $7 \%$ via seven steps. The ${ }^{13} \mathrm{C}$ NMR data in $\mathrm{CDCl}_{3}$ (cf. Supporting Information File 1) were identical to previously reported data [38].
The allyl alcohol 26 was also used in a Sharpless epoxidation with (-)-D-DET to give $\mathbf{2 7 b}$ that was converted into $(4 S, 5 R, 6 S)-11 d$ via the same sequence of steps with a total yield of $6 \%$ via seven steps. Starting from the alcohol $\mathbf{2 4}$, two more 


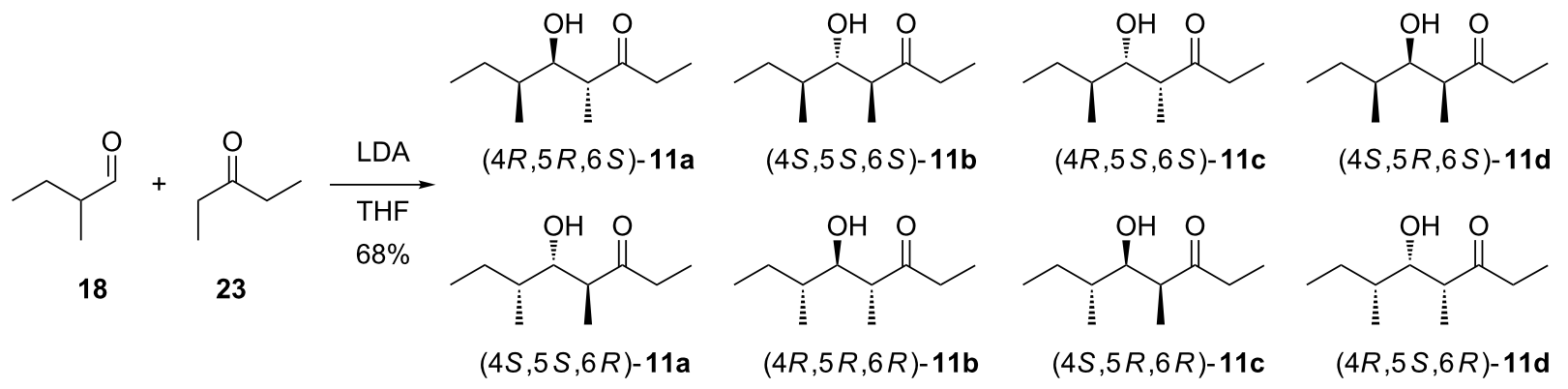

Scheme 4: Synthesis of a racemic mixture of all four diastereomers of 11.

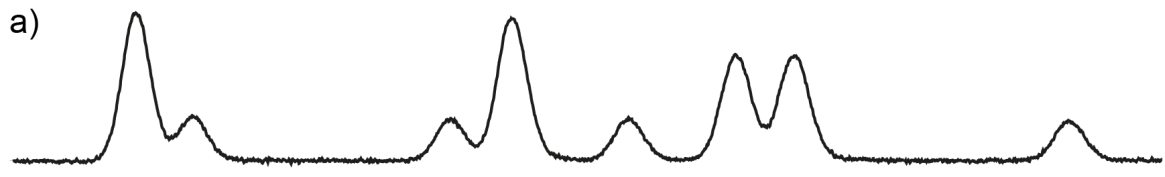

b)

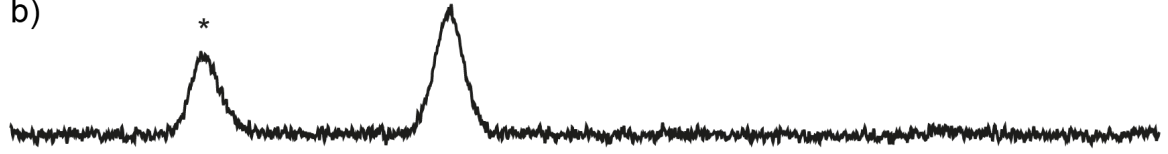

c) $\quad(4 R, 5 S, 6 S)-11 \mathrm{c}$

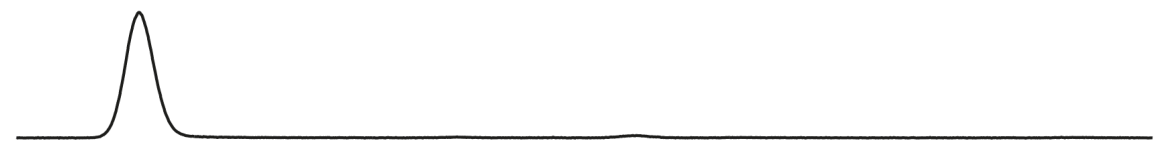

d)

$(4 S, 5 R, 6 S)-11 d$

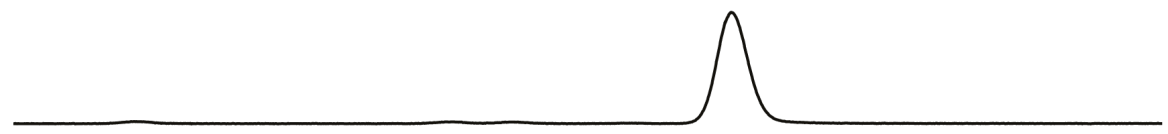

e)

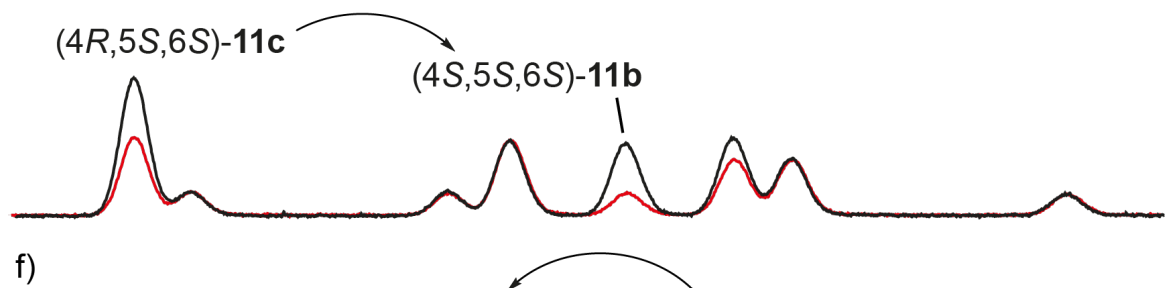

f)

$(4 R, 5 R, 6 S)-11 \mathrm{a} \quad(4 S, 5 R, 6 S)-11 \mathrm{~d}$

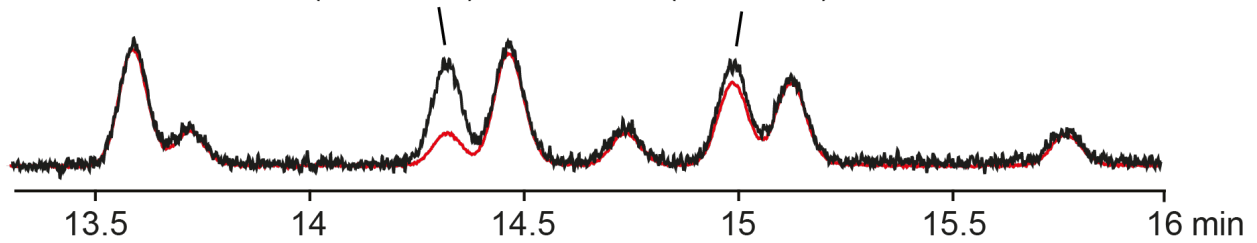

Figure 3: Gas chromatographic analysis of 11 on a homochiral stationary phase. a) Synthetic mixture of all eight stereoisomers (Scheme 4), b) headspace extract from $D$. clavata, c) enantioselectively synthesised (4R,5S,6S)-11c (Scheme 5), d) enantioselectively synthesised (4S,5R,6S)-11d (Scheme 5), e) coinjection of a) and epimerisation products of (4R,5S,6S)-11c (Scheme 6), and f) coinjection of a) and epimerisation products of $(4 S, 5 R, 6 S)-11 d$ (Scheme 6$)$. The peak labelled with asterisk represents the second main natural product in the headspace extracts from $D$. clavata, also labelled by asterisk in Figure 1. For comparison, the relative proportions of the eight stereoisomers obtained by synthesis according to Scheme 4 are indicated by the red curve in $\mathrm{e}$ ) and $\mathrm{f}$ ). 


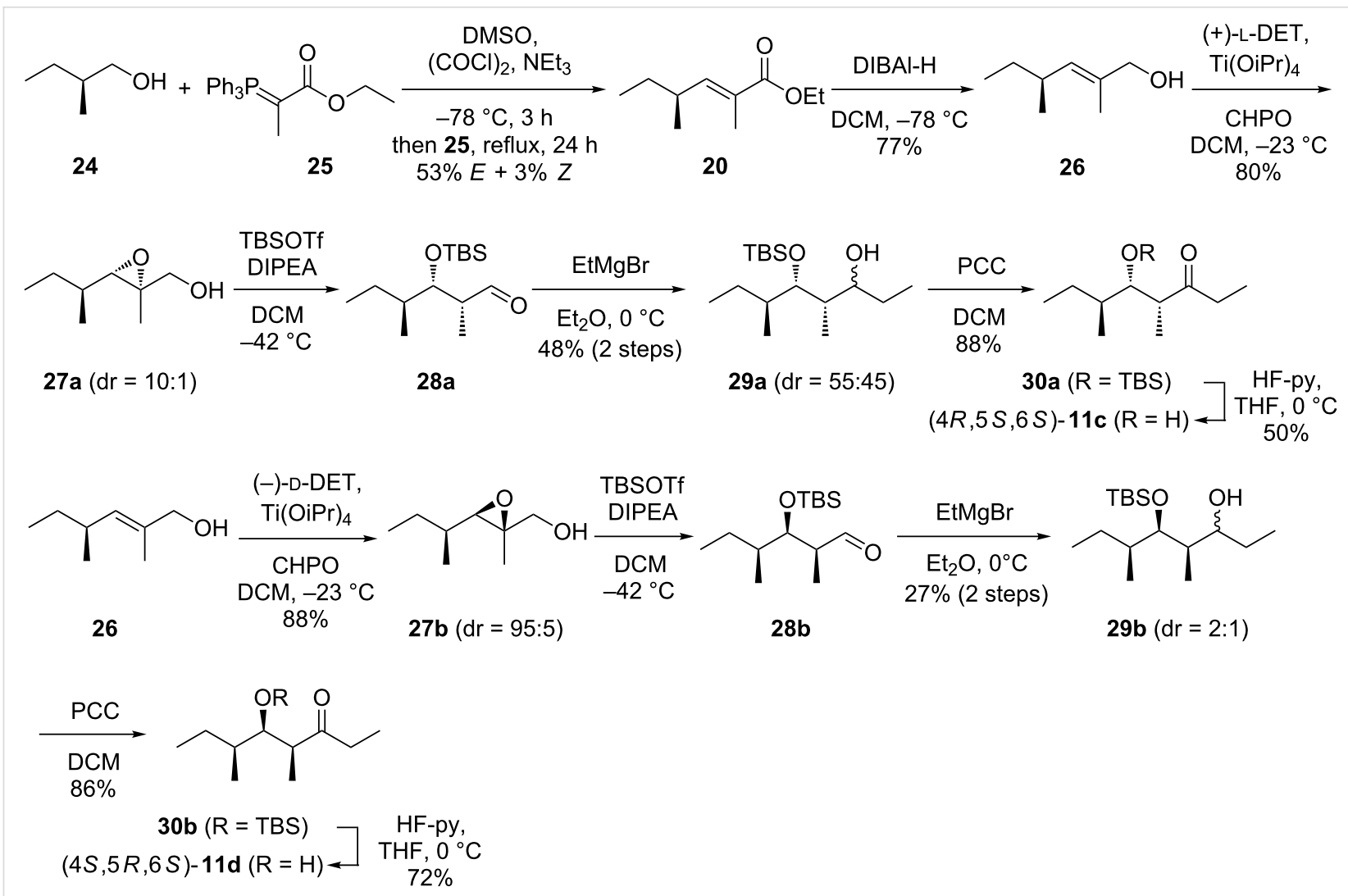

Scheme 5: Enantioselective synthesis of $(4 R, 5 S, 6 S)-11 \mathrm{c}$ and $(4 S, 5 R, 6 S)-11 \mathrm{~d}$.

stereoisomers, $(4 R, 5 R, 6 S)-\mathbf{1 1} \mathbf{a}$ and $(4 S, 5 S, 6 S)-\mathbf{1 1} \mathbf{b}$, would be accessible via the same route from $(2 Z, 4 S)-\mathbf{2 0}$, but this compound was not obtained in sufficient quantity for a practical approach towards 11a and 11b. Therefore, these two stereoisomers were obtained by epimerisation at the $\alpha$-carbon (C-4) under mildly basic conditions (Scheme 6). Following this approach, the epimerisation of $(4 R, 5 S, 6 S)$-11c yielded $(4 S, 5 S, 6 S)$ 11b, while epimerisation of $(4 S, 5 R, 6 S)$-11 d gave $(4 R, 5 R, 6 S)$ 11a. The epimerisation products were added to the synthetic mixture of all eight stereoisomers, showing by enantioselective $\mathrm{GC}$ analysis that the natural product was identical to $(4 R, 5 R, 6 S)-11$ a (Figure 3).

For the chemical characterisation of all eight stereoisomers of 11 the mixture obtained by the reaction shown in Scheme 4 was separated by extensive chromatographic purification. Compound 11c was readily separated from the mixture of $11 \mathbf{a}, \mathbf{1 1 b}$ and 11d by simple column chromatography on silica gel. Preparative reversed-phase HPLC allowed for a separation of all three compounds 11a, 11b and 11d. Subsequent preparative HPLC using a homochiral stationary phase gave access to the pure enantiomers of these three compounds, but unfortunately not of 11c. However, as described above, enantiomerically pure $(4 R, 5 S, 6 S)-11 \mathbf{c}$ was obtained by enantioselective synthesis, and

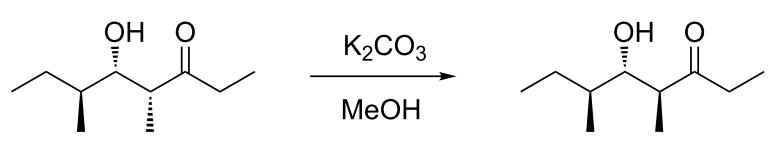

$(4 R, 5 S, 6 S)-11 \mathrm{c}$

$(4 S, 5 S, 6 S)-11 b$<smiles>CCC(=O)C(C)[C@H](O)[C@H](C)CC</smiles>

$(4 S, 5 R, 6 S)-11 \mathbf{d}$

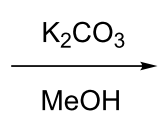<smiles>CCC(=O)[C@H](C)[C@H](O)[C@H](C)CC</smiles>

$(4 R, 5 R, 6 S)-11 \mathbf{a}$
Scheme 6: Epimerisations of (4R,5S,6S)-11c and $(4 S, 5 R, 6 S)-11 d$ under basic conditions.

the peaks for the enantiomers of $\mathbf{1 1} \mathbf{c}$ in the GC analysis on a homochiral stationary phase could be readily assigned by comparison to synthetic $(4 R, 5 S, 6 S)-11 \mathrm{c}$. Finally, a structure could be assigned to each of the eight peaks observed in this analysis, again confirming the structure of $(4 R, 5 R, 6 S)$-11a for the natural product from D. clavata (Figure 4 ). The ${ }^{13} \mathrm{C}$ NMR data of all four stereoisomers 11a-d are summarised in Table 2. 

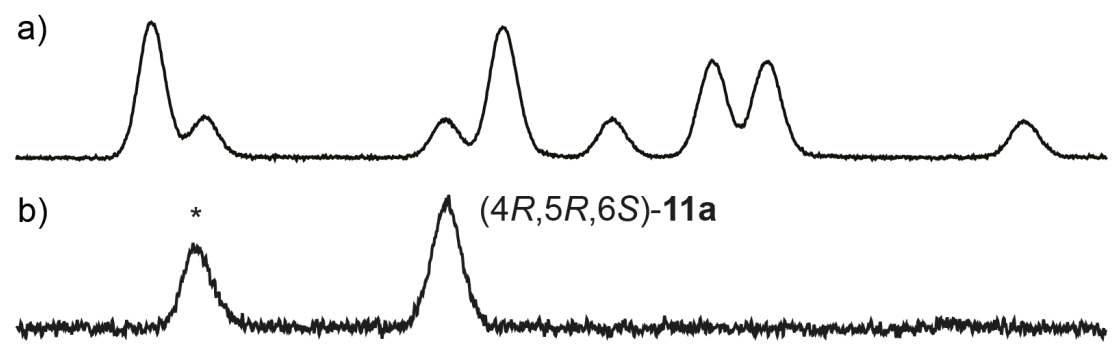

c)

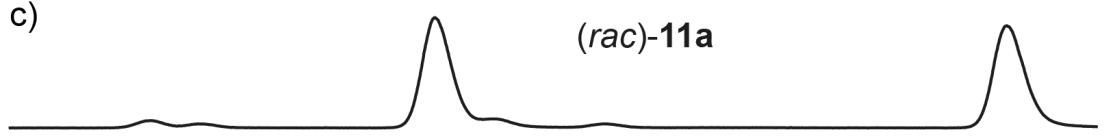

d)

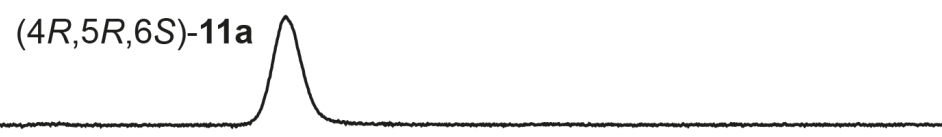

e)

$(4 S, 5 S, 6 R)-11 \mathrm{a}$

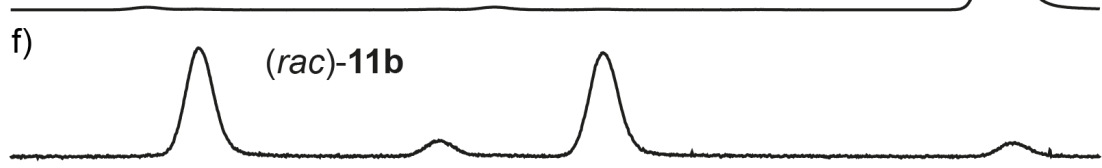

g) $\bigwedge(4 S, 5 S, 6 S)-11 b$

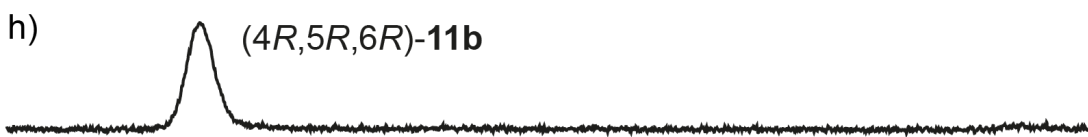

i)

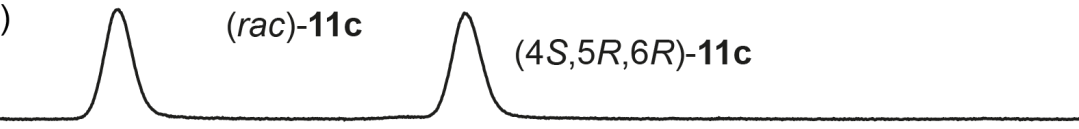

j)

$\bigwedge(4 R, 5 S, 6 S)-11 \mathrm{c}$

k)
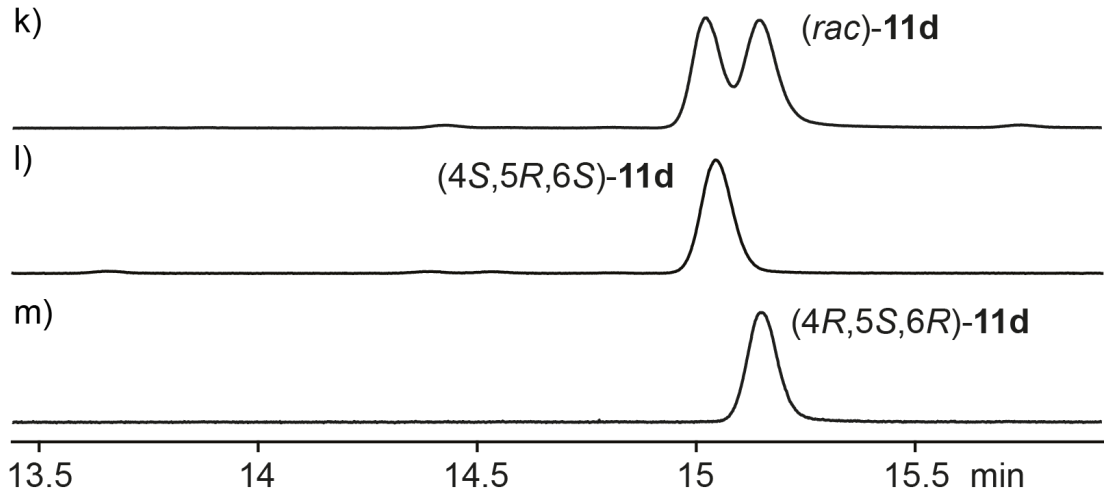

Figure 4: Gas chromatographic analysis of 11 on a homochiral stationary phase. a) Synthetic mixture of all eight stereoisomers (Scheme 4), b) headspace extract from $D$. clavata, and $\mathrm{c})-\mathrm{m}$ ) pure racemates and enantiomers of 11a-d. Compound (4R,5S,6S)-11c was obtained by enantioselective synthesis (Scheme 5), the pure racemates of 11a-d and the pure enantiomers of 11a, 11b and 11d were obtained by chromatographic separation from the synthetic mixture of all eight stereoisomers. The peak labelled with asterisk represents the second main natural product in the headspace extracts from $D$. clavata, also labelled by asterisk in Figure 1. 
Table 2: ${ }^{13} \mathrm{C}$ NMR data (chemical shifts in ppm) for $11 \mathrm{a}-\mathbf{d}(125 \mathrm{MHz}$, $\left.\mathrm{C}_{6} \mathrm{D}_{6}\right)$.

\begin{tabular}{lllll} 
carbon & $\mathbf{1 1 a}$ & $\mathbf{1 1 b}$ & $\mathbf{1 1 c}$ & $\mathbf{1 1 d}$ \\
\hline C-1 & 7.7 & 7.7 & 7.8 & 7.8 \\
C-2 & 36.1 & 36.2 & 34.6 & 34.9 \\
C-3 & 215.0 & 215.6 & 215.4 & 214.5 \\
C-4 & 48.8 & 47.7 & 47.3 & 48.2 \\
C-5 & 75.8 & 78.4 & 74.6 & 74.7 \\
C-6 & 37.0 & 38.1 & 37.3 & 37.5 \\
C-7 & 27.1 & 23.6 & 25.4 & 26.2 \\
C-8 & 12.0 & 11.8 & 9.3 & 11.2 \\
4-Me & 12.4 & 14.7 & 11.3 & 11.4 \\
6-Me & 13.9 & 16.3 & 15.0 & 14.5
\end{tabular}

A proposed biosynthetic pathway to $(4 R, 5 R, 6 S)-11 \mathrm{a}$ is shown in Scheme 7 that is likely performed by a typical fungal iterative polyketide synthase (PKS). Starting from acyl-carrier-protein (ACP) bound acetate a first elongation step with malonyl-SCoA (Mal-SCoA) catalysed by an acyl transferase (AT) and a ketosynthase (KS) domain yields acetoacetyl-SACP. This may be followed by SAM-dependent C-methylation by a methyl transferase domain (MT). The stereochemical course for this reaction can be inferred from the $4 R$-configuration of the final product 11a, if indeed an iterative PKS is involved that should have the same stereochemical course for the corresponding reactions in each chain extension step. A keto-reductase (KR) installs the 3-hydroxy group with the same stereochemistry as observed at C-5 in 11a. This is followed by elimination of water by a dehydratase domain (DH) and reduction of the $\mathrm{C}=\mathrm{C}$ double bond by an enoyl reductase (ER) with installation of the stereocentre in intermediate A corresponding to C-6 of 11a. The next chain extension with malonyl-SCoA and methylation proceeds with the same stereochemical courses as discussed above, but stops after action of the KR to yield intermediate $\mathbf{B}$ in which all the stereocentres that occur in 11a are already defined. A third extension with malonyl-SCoA and methylation gives rise to intermediate $\mathbf{C}$ that can be released, e.g., by a thioesterase to the $\beta$-keto acid $\mathbf{D}$, followed by spontaneous decarboxylation to 11a. Two structurally related molecules to $\mathbf{1 1 a}$ have been reported from endophytic Nodulisporium spp. (shown in the box in Scheme 7) [28,39] that may be formed by a similar PKS. Further investigations are required to identify the PKSs for this family of metabolites and to confirm the hypothetical biosynthesis as shown in Scheme 7.

The volatile 9, a compound emitted in small amounts by D. clavata, showed a mass spectrum that was not included in our database (Figure 5A). However, the mass spectrum of 6-propyl-5,6-dihydro-2H-pyran-2-one (Figure $5 \mathrm{~B}$ ) is very similar, and the mass difference for the molecular ion of $28 \mathrm{Da}$ suggested the structure of 6-methyl-5,6-dihydro- $2 \mathrm{H}$-pyran-2-one for compound 9 . This compound was synthesised by esterification of pent-4-en-2-ol (31) with acryloyl chloride (32) to $\mathbf{3 3 ,}$ followed by ring-closing metathesis using the Hoveyda-Grubbs catalyst of the second generation (Scheme 8). The synthetic material proved to be identical to the volatile of $D$. clavata, thereby establishing its identity.
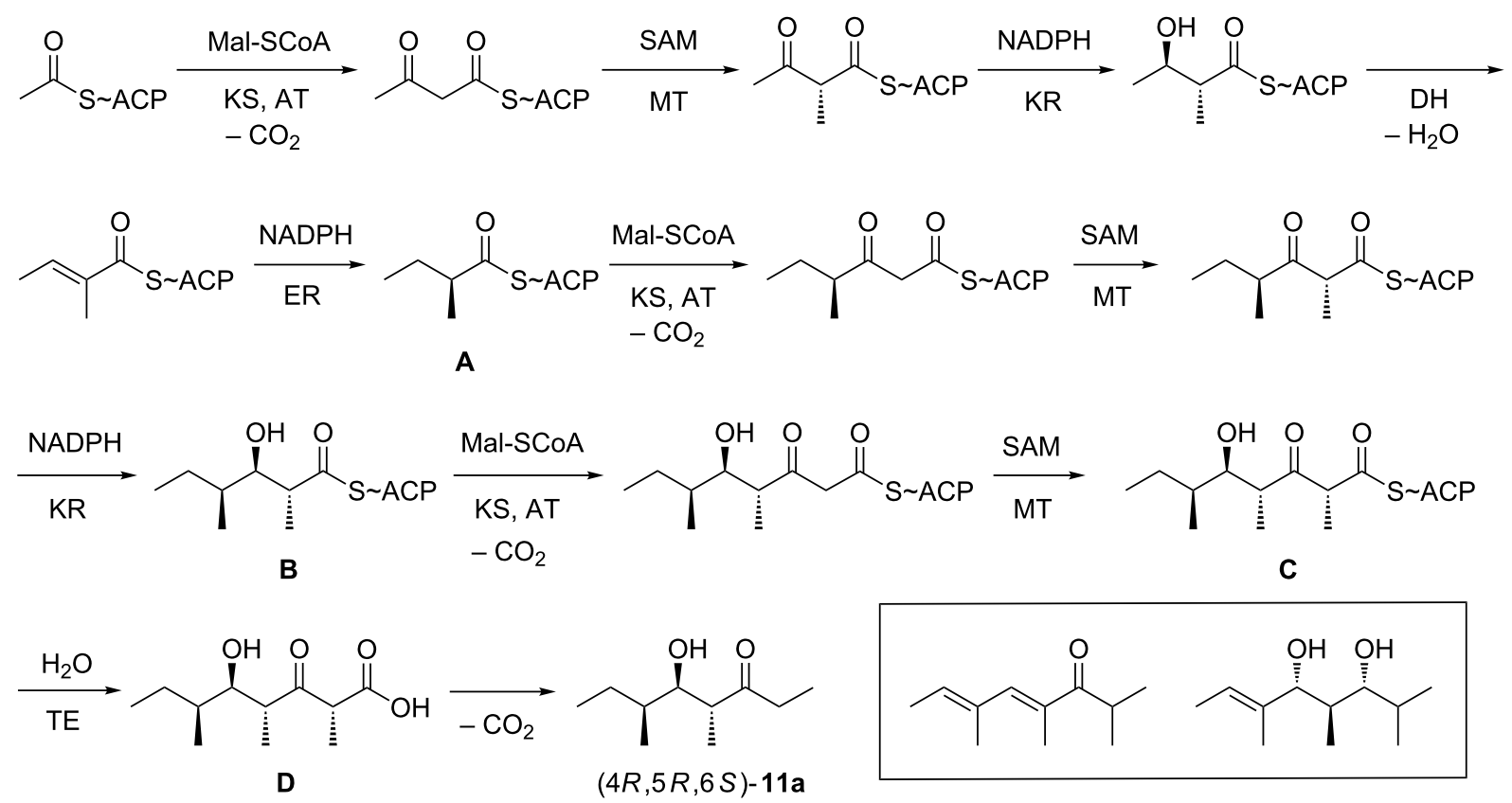

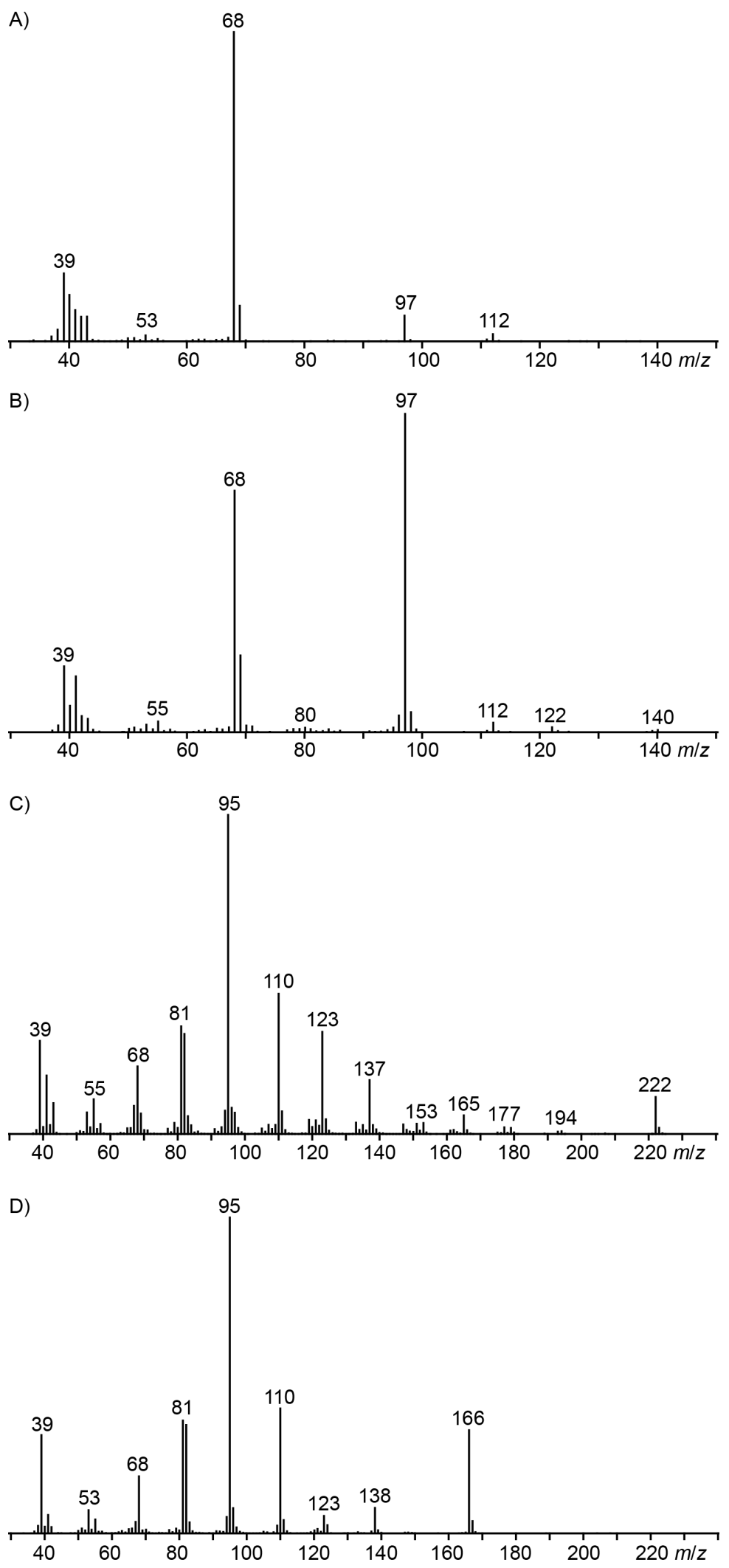

Figure 5: Mass spectra of a) 6-methyl-5,6-dihydro-2H-pyran-2-one (9), b) 6-propyl-5,6-dihydro-2H-pyran-2-one, c) 6-nonyl-2H-pyran-2-one (17), and d) 6-pentyl-2H-pyran-2-one. 
<smiles>C=CCC(C)OC(=O)C=CC(C)OC(=O)O[Mg]</smiles><smiles>C#CCCCCCCCCC</smiles>

Scheme 8: Synthesis of 6-methyl-5,6-dihydro-2H-pyran-2-one (9) and 6-nonyl-2H-pyran-2-one (17).

Finally, major amounts of a compound were emitted by D. clavata whose mass spectrum showed strong similarities to the mass spectrum of 2 (Figure $5 \mathrm{C}$ and 5D). The mass difference of $56 \mathrm{Da}$ for the molecular ion pointed to four additional methylene units, suggesting the structure of 6-nonyl- $2 \mathrm{H}$-pyran2-one (17). For comparison a synthetic reference compound was prepared from undec-1-yne (34) and propiolic acid (35) in a gold-catalysed reaction developed by Schreiber and co-workers [40] (Scheme 8). Synthetic 17 and the volatile from D. clavata showed the same mass spectrum and retention time, confirming their identity. The newly identified natural product 17 further extends the number of known 6-alkyl-2H-pyran-2-ones: While the mixture of 6-propyl-, 6-pentyl- and 6-heptyl-2H-pyran-2one occurs in Trichoderma viride [41], higher homologs have not been reported as natural products so far.

\section{Biological characterisation of compounds}

Three of the volatile metabolites identified from $D$. clavata (compounds 9, 14 and 17) were evaluated for antimicrobial and cytotoxic activities using a standard panel of fungi and bacteria, as well as the murine cell line L929 (Table 3). The 2-pyrone 17 exhibited a moderate antifungal and weak antibacterial effect, while the lactone 9 was moderately cytotoxic, but devoid of significant antimicrobial activity. The chlorinated aromatic com-

Table 3: In vitro antibacterial, antifungal and cytotoxic activity of compounds $\mathbf{9 , 1 4}$ and 17 in comparison with positive controls.

\begin{tabular}{|c|c|c|c|c|}
\hline Test organism & $9^{a}$ & $14^{a}$ & $17^{a}$ & Reference \\
\hline \multicolumn{5}{|l|}{ Fungi } \\
\hline Candida albicans DSM 1665 & - & - & 16.6 & $33.3^{\mathrm{b}}$ \\
\hline Mucor hiemalis DSM 2656 & 33.3 & - & 16.6 & $5.25-16.6^{b}$ \\
\hline Pichia anomala DSM 70255 & - & - & 33.3 & $33.3^{\mathrm{b}}$ \\
\hline Rhodotorula glutinis DSM 10134 & - & - & 16.6 & $0.52-16.7^{b}$ \\
\hline Schizosaccharomyces pombe DSM 70572 & - & - & 16.6 & $42.0-67.0^{b}$ \\
\hline
\end{tabular}

\section{Bacteria}

\begin{tabular}{|c|c|c|c|c|}
\hline Bacillus subtilis DSM 10 & - & - & 67.0 & $6.7-8.3^{\mathrm{c}}$ \\
\hline Chromobacterium violaceum DSM 30191 & 67.0 & - & - & $0.83-8.3^{\mathrm{c}}$ \\
\hline Escherichia coli DSM 1116 & - & - & - & $0.83^{\mathrm{C}}$ \\
\hline Micrococcus luteus DSM 20030 & - & - & - & $0.42^{\mathrm{C}}$ \\
\hline Mycobacterium sp. DSM 43270 & - & - & - & $2.1^{\mathrm{c}}$ \\
\hline Pseudomonas aeruginosa DSM 50071 & - & - & - & $16.6-21.0^{d}$ \\
\hline Staphylococcus aureus DSM 346 & - & - & 67.0 & $0.1-0.21^{\mathrm{c}}$ \\
\hline \multicolumn{5}{|l|}{ Eukaryotic cell line } \\
\hline Murine cell line L929 & $>10$ & 6 & $>10$ & $1 \mathrm{~nm}^{\mathrm{e}}$ \\
\hline
\end{tabular}

a For compound testings against bacteria and fungi minimum inhibitory concentrations (MIC) in $\mu g \mathrm{~mL}^{-1}$ are given, for cytotoxicity testings against the murine cell line the $\mathrm{IC}_{50}$ is given in $\mu \mathrm{g} \mathrm{mL}{ }^{-1}$. Reference compounds: ${ }^{b}$ nystatin, ${ }^{\mathrm{C}}$ oxytetracyclin hydrochloride, ${ }^{\mathrm{d}}$ gentamycin, ${ }^{\mathrm{e}}$ epothilon $\mathrm{B}$. 
pound $\mathbf{1 4}$ only weakly inhibited the sensitive test organisms Chromobacterium violaceum and Mucor hiemalis.

\section{Conclusion}

The current study provides evidence that manifold new volatiles may be encountered in the future through a systematic study of Xylariales and other predominant fungal endophytes. As many of these fungi show interesting activities in screening approaches for biocontrol agents, and some of them are even under development for commercial applications, such studies not only complement the knowledge on the metabolic capabilities, but may even become mandatory in order to provide final proof for the safety of the organisms. There have been some studies on VOC-producing xylarialean endophytes with significant activities against competing microbes, but the volatile profiles of these biocontrol candidates were only evaluated using databases like NIST, which can only serve to detect and identify known compounds. The current study demonstrates the need of chemical synthesis for rigorous identification of new compounds. Some of these metabolites were tested for biological effects and found to display only weak activities in biological systems, providing evidence for their safety. In addition, none of the volatiles detected here represents a metabolite that is biosynthetically linked to a known class of hazardous mycotoxins. Similar studies on other fungal cultures with proven initial antagonistic activities that can be related to VOCs will probably be rewarding.

\section{Supporting Information}

\section{Supporting Information File 1}

Experimental details, synthetic procedures, and spectroscopic data for synthetic compounds.

[http://www.beilstein-journals.org/bjoc/content/ supplementary/1860-5397-14-9-S1.pdf]

\section{Acknowledgements}

This work was funded by the Deutsche Forschungsgemeinschaft (DI1536/9-1) and by the State of Lower Saxony with a Ph.D. scholarship in the frame of the MINAS graduate school (to TW). We thank Andreas Schneider für HPLC separation of the stereoisomers of $\mathbf{1 1}$.

\section{ORCID ${ }^{\circledR}$ iDs}

Jeroen S. Dickschat - https://orcid.org/0000-0002-0102-0631

\section{References}

1. Dickschat, J. S. Nat. Prod. Rep. 2017, 34, 310-328. doi:10.1039/C7NP00003K
2. Murahashi, S. Sci. Pap. Inst. Phys. Chem. Res. (Jpn.) 1938, 34, 155-172.

3. Zawirksa-Wojtasiak, R. Food Chem. 2004, 86, 113-118. doi:10.1016/j.foodchem.2003.08.016

4. Wurzenberger, M.; Grosch, W. Z. Lebensm.-Unters. Forsch. 1983, 176, 16-19. doi:10.1007/BF01089340

5. Collins, R. P.; Halim, A. F. J. Agric. Food Chem. 1972, 20, 437-438. doi:10.1021/jf60180a010

6. Vinale, F.; Sivasithamparam, K.; Ghisalberti, E. L.; Marra, R.; Barbetti, M. J.; Li, H.; Woo, S. L.; Lorito, M. Physiol. Mol. Plant Pathol. 2008, 72, 80-86. doi:10.1016/j.pmpp.2008.05.005

7. Jeleń, H. H. J. Agric. Food Chem. 2002, 50, 6569-6574. doi:10.1021/jf020311o

8. Riclea, R.; Dickschat, J. S. Angew. Chem., Int. Ed. 2015, 54, 12167-12170. doi:10.1002/anie.201506128

9. Brock, N. L.; Dickschat, J. S. ChemBioChem 2013, 14, 1189-1193. doi:10.1002/cbic.201300254

10. Zamir, L. O.; Gauthier, M. J.; Devor, K. A.; Nadeau, Y.; Sauriol, F. J. Chem. Soc., Chem. Commun. 1989, 598-600. doi:10.1039/c39890000598

11. Brock, N. L.; Tudzynski, B.; Dickschat, J. S. ChemBioChem 2011, 12, 2667-2676. doi:10.1002/cbic.201100516

12. Bömke, C.; Tudzynski, B. Phytochemistry 2009, 70, 1876-1893. doi:10.1016/j.phytochem.2009.05.020

13. Maharachchikumbura, S. S. N.; Hyde, K. D.; Jones, E. B. G.; McKenzie, E. H. C.; Bhat, J. D.; Dayarathne, M. C.; Huang, S.-K.; Norphanphoun, C.; Senanayake, I. C.; Perera, R. H.; Shang, Q.-J.; Xiao, Y.; D'souza, M. J.; Hongsanan, S.; Jayawardena, R. S.; Daranagama, D. A.; Konta, S.; Goonasekara, I. D.; Zhuang, W.-Y.; Jeewon, R.; Phillips, A. J. L.; Abdel-Wahab, M. A.; Al-Sadi, A. M.; Bahkali, A. H.; Boonmee, S.; Boonyuen, N.; Cheewangkoon, R.; Dissanayake, A. J.; Kang, J.; Li, Q.-R.; Liu, J. K.; Liu, X. Z.; Liu, Z.-Y.; Luangsa-ard, J. J.; Pang, K.-L.; Phookamsak, R.; Promputtha, I.; Suetrong, S.; Stadler, M.; Wen, T.; Wijayawardene, N. N. Fungal Diversity 2016, 79, 1-317. doi:10.1007/s13225-016-0369-6

14. Wendt, L.; Sir, E. B.; Kuhnert, E.; Heitkämper, S.; Lambert, C.; Hladki, A. I.; Romero, A. I.; Luangsa-ard, J. J.; Srikitikulchai, P.; Peršoh, D.; Stadler, M. Mycol. Prog. 2017. doi:10.1007/s11557-017-1311-3

15. Daranagama, D. A.; Hyde, K. D.; Sir, E. B.; Thambugala, K. M.; Tian, Q.; Samarakoon, M. C.; McKenzie, E. H. C.; Jayasiri, S. C.; Tibpromma, S.; Bhat, J. D.; Liu, X.; Stadler, M. Fungal Diversity 2017. doi:10.1007/s13225-017-0388-y

16. Pažoutová, S.; Follert, S.; Bitzer, J.; Keck, M.; Surup, F.; Šrůtka, P.; Holuša, J.; Stadler, M. Fungal Diversity 2013, 60, 107-123. doi:10.1007/s13225-013-0238-5

17. Grob, K.; Zürcher, F. J. Chromatogr. 1976, 117, 285-294. doi:10.1016/0021-9673(76)80005-2

18. Adams, R. P. Identification of Essential Oil Components by Gas Chromatography/Mass Spectrometry; Allured: Carol Stream, 2009.

19. Anke, H.; Stadler, M.; Mayer, A.; Sterner, O. Can. J. Bot. 1995, 73, 932-939. doi:10.1139/b95-341

20. Wang, F.; Liu, J.-K. Helv. Chim. Acta 2004, 87, 2131-2134. doi:10.1002/hlca.200490193

21. Wang, G.; Fan, J.-Y.; Zhang, W.-J.; Hua, C.-P.; Chen, C.-J.; Yan, W.; Ge, H.-M.; Jiao, R.-H.; Tan, R.-X. Chem. Biodiversity 2015, 12 , 1349-1355. doi:10.1002/cbdv.201400414

22. Nadeau, A. K.; Sorensen, J. L. Tetrahedron Lett. 2011, 52, 1697-1699. doi:10.1016/j.tetlet.2011.01.150 
23. Pathania, A. S.; Guru, S. K.; UI Ashraf, N.; Riyaz-UI-Hassan, S.; Ali, A.; Tasduq, S. A.; Malik, F.; Bhushan, S. Eur. J. Pharmacol. 2015, 765, 75-85. doi:10.1016/j.ejphar.2015.08.018

24. Hussain, H.; Root, N.; Jabeen, F.; Al-Harrasi, A.; Ahmad, M.; Mabood, F.; Hassan, Z.; Shah, A.; Green, I. R.; Schulz, B.; Krohn, K. Chem. Biodiversity 2015, 12, 289-294. doi:10.1002/cbdv.201400098

25. Zilla, M. K.; Qadri, M.; Pathania, A. S.; Strobel, G. A.; Nalli, Y.; Kumar, S.; Guru, S. K.; Bhushan, S.; Singh, S. K.; Vishwakarma, R. A.; Riyaz-UI-Hassan, S.; Ali, A. Phytochemistry 2013, 95, 291-297. doi:10.1016/j.phytochem.2013.06.021

26. Wu, Z.-C.; Li, D.-L.; Chen, Y.-C.; Zhang, W.-M. Helv. Chim. Acta 2010, 93, 920-924. doi:10.1002/hlca.200900307

27. Pongcharoen, W.; Rukachaisirikul, V.; Phongpaichit, S.; Kühn, T.; Pelzing, M.; Sakayaroj, J.; Taylor, W. C. Phytochemistry 2008, 69, 1900-1902. doi:10.1016/j.phytochem.2008.04.003

28. Dai, J.; Krohn, K.; Flörke, U.; Draeger, S.; Schulz, B.; Kiss-Szikszai, A.; Antus, S.; Kurtán, T.; van Ree, T. Eur. J. Org. Chem. 2006, 3498-3506. doi:10.1002/ejoc.200600261

29. Stadler, M.; Læssøe, T.; Fournier, J.; Decock, C.; Schmieschek, B.; Tichy, H.-V.; Peršoh, D. Stud. Mycol. 2014, 77, 1-143. doi:10.3114/sim0016

30. Hikino, H.; Ito, K.; Takemoto, T. Chem. Pharm. Bull. 1968, 16, 1608-1610. doi:10.1248/cpb.16.1608

31. Amand, S.; Langenfeld, A.; Blond, A.; Dupont, J.; Nay, B.; Prado, S. J. Nat. Prod. 2012, 75, 798-801. doi:10.1021/np2009913

32. Barra, L.; Schulz, B.; Dickschat, J. S. ChemBioChem 2014, 15, 2379-2383. doi:10.1002/cbic.201402298

33. van Beek, T. A.; Joulain, D. Flavour Fragrance J. 2018, 33, 6-51. doi:10.1002/ffj.3418

34. Liu, Y.; Xu, X.-I.; Zhou, G.-h. Int. J. Food Sci. Technol. 2007, 42, 543-550. doi:10.1111/j.1365-2621.2006.01264.x

35. Wang, T.; Rabe, P.; Citron, C. A.; Dickschat, J. S. Beilstein J. Org. Chem. 2013, 9, 2767-2777. doi:10.3762/bjoc.9.311

36. Curtis, R. F.; Land, D. G.; Griffiths, N. M.; Gee, M.; Robinson, D.; Peel, J. L.; Dennis, C.; Gee, J. M. Nature 1972, 235, 223-224. doi:10.1038/235223a0

37. Jung, M. E.; D'Amico, D. C. J. Am. Chem. Soc. 1993, 115, 12208-12209. doi:10.1021/ja00078a087

38. Paterson, I.; Hulme, A. N. J. Org. Chem. 1995, 60, 3288-3300. doi:10.1021/jo00116a010

39. Dai, J.; Krohn, K.; Draeger, S.; Schulz, B. Eur. J. Org. Chem. 2009, 1564-1569. doi:10.1002/ejoc.200801106

40. Luo, T.; Dai, M.; Zheng, S.-L.; Schreiber, S. L. Org. Lett. 2011, 13, 2834-2836. doi:10.1021/ol200794w

41. Wickel, S. M.; Citron, C. A.; Dickschat, J. S. Eur. J. Org. Chem. 2013, 2906-2913. doi:10.1002/ejoc.201300049

\section{License and Terms}

This is an Open Access article under the terms of the Creative Commons Attribution License (http://creativecommons.org/licenses/by/4.0), which permits unrestricted use, distribution, and reproduction in any medium, provided the original work is properly cited.

The license is subject to the Beilstein Journal of Organic Chemistry terms and conditions:

(http://www.beilstein-journals.org/bjoc)

The definitive version of this article is the electronic one which can be found at:

doi:10.3762/bjoc.14.9 